\title{
Erratum to: Boundary element analysis of post-tensioned slabs
}

\author{
Youssef F. Rashed $^{1,2} \cdot$ Moustafa Swidan ${ }^{3}$ Wael M. EL-Degwy ${ }^{4}$
}

Published online: 24 October 2016

(c) The Author(s) 2016. This article is published with open access at Springerlink.com

\section{Erratum to: Int J Adv Struct Eng (2015) 7:143-158 DOI 10.1007/s40091-015-0088-3}

Two authors were missing in the original article. Here is the complete author list.

Youssef F. Rashed

Supreme Council of Universities, Giza, Egypt and

Department of Structural Engineering, Cairo University, Giza, Egypt

yrashed@hotmail.com; yrashed@eng.cu.edu.eg

Moustafa Swidan

Faculty of Engineering

Cairo University

Giza, Egypt

Moustafa.Swidan@dargroup.com

The online version of the original article can be found under doi:10.1007/s40091-015-0088-3.

Youssef F. Rashed

yrashed@hotmail.com; yrashed@eng.cu.edu.eg

Moustafa Swidan

Moustafa.Swidan@dargroup.com; maswidan@hotmail.com

Wael M. EL-Degwy

wmeldegwy@hotmail.com

1 Supreme Council of Universities, Giza, Egypt

2 Department of Structural Engineering, Cairo University, Giza, Egypt

3 Faculty of Engineering, Cairo University, Giza, Egypt

4 Structural Engineering Department, Faculty of Engineering, Cairo University, Giza, Egypt
Wael M. EL-Degwy

Structural Engineering Department

Faculty of Engineering

Cairo University

Giza, Egypt

wmeldegwy@hotmail.com

Open Access This article is distributed under the terms of the Creative Commons Attribution 4.0 International License (http://crea tivecommons.org/licenses/by/4.0/), which permits unrestricted use, distribution, and reproduction in any medium, provided you give appropriate credit to the original author(s) and the source, provide a link to the Creative Commons license, and indicate if changes were made. 